\title{
TÓPICA, DERECHO Y MÉTODO JURÍDICO
}

\section{Introducción}

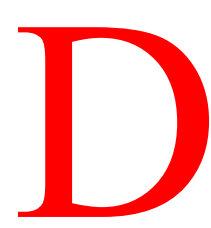

esde que en 1953 Theodor Viehweg publicara la primera edición de su obra capital, Topik und Jurisprudenz, la noción de tópica jurídica se erige en concepto recurrente y archirrepetido en la teoría del derecho, especialmente en lo relacionado con la metodología jurídica. Fuera de Alemania, las alusiones ni siquiera se atienen a ese hilo conductor de la metodología, y ponen a la tópica jurídica en relación con los más variados asuntos de la teoría del derecho, desde el derecho natural hasta los principios generales del derecho o la polémica sobre la cientificidad de la dogmática jurídica.

Pierde de esta manera el concepto todo perfil claro y parece quedar reducido a simple recurso de estilo o concesión a la moda en la doctrina del derecho, o a mero «tópico» o «lugar común», apto para apoyar cualquier tesis o cualquier enfoque con el aura de su sugerente inconcreción. Mas condenar por ello, y sin más, la construcción de Vichweg en torno a esa noción sería negar el protagonismo y la importancia al autor de la teoría en razón de las desviaciones de sus exégetas. Por otra parte, esa heterogeneidad de enfoques e interpretaciones a que la doctrina de Vichweg ha dado lugar, además de no ser óbice, sino todo lo contrario, para una vuelta al estudio de sus planteamientos originarios y su evolución en el propio Vichweg, no le resta un alto valor a algunos de esos desarrollos posteriores en otros autores ni hace menos impresionante la nómina de grandes tratadistas que han teorizado sobre la tópica jurídica o la han integrado de modo fructífero en sus construcciones. Piénsese sino en nombres como Josef Esser, Martin Kriele, Friedrich Müller, Franz Wieacker, Konrad Hesse o Chaim Perelman.

No puede desconocerse, pese a lo dicho, que ese confusionismo obedece a los caracteres de la propia doctrina de Viehweg. Su obra fundamental citada es hermosa en su construcción, pero sumamente inconcreta y de perfiles borrosos en cuanto a la delimitación de sus categorías conceptuales más importantes y en cuanto al alcance y extensión de su campo de aplicaciones. A esa obra se suman, en Viehweg, una serie de artículos de tema diverso, en los que casi siempre se toma la tópica como referente o punto de partida, pero cuyas contribuciones a esta doctrina son también sumamente generales, fragmentarias y hasta cambiantes. Y el panorama se complica aún más si se tiene en cuenta que quienes fueron sus discípulos y colaboradores próximos, constituyendo el que a veces se llamó «Grupo de Mainz» (Ballweg, Schreckenberger, Seibert, Rodingen, etc.), llevan a cabo casi siempre adaptaciones de las doctrinas de Viehweg a campos diversos, como la semiótica jurídica, la teoría de 
la comunicación jurídica, la retórica jurídica, el análisis empírico de las argumentaciones jurídicas, etc. Con todo ello el tema gana en complejidad y se dificulta aún más la obtención de una perspectiva uniforme y congruente sobre la tópica jurídica.

Sin embargo, las dificultades expuestas no son sino otras tantas razones de la necesidad de un estudio de conjunto y de intentar descubrir, al menos, las líneas maestras de la doctrina, sus implicaciones reales para la teoría del derecho y su mayor o menor utilidad en los campos teóricos o en la práctica jurídica.

En el intento de abrir una vía hacia tales objetivos, comenzaremos por exponer las líneas centrales de la teorización de Viehweg sobre la tópica para, a continuación, profundizar en la idea del derecho subyacente y en sus implicaciones para la teoría jurídica en general y para la metodología jurídica en particular. ${ }^{1}$

\section{Caracteres generales de la tópica jurídica en Viehweg.}

Puestos a estructurar la doctrina de Viehweg en torno a algunos caracteres básicos, se pueden elegir los siguientes: el papel otorgado a los conceptos de «problema» y «aporía», la orientación antisistemática y antilogicista, y la relevancia del concepto de topos o tópico.

1. 1. «Problema»y «aporía».

La descripción que Viehweg hace del «modo de pensar» tópico en el derecho tiene sus ejes principales en las nociones de «problema» y «aporía». La tópica es, para Viehweg, una «técnica de pensamiento» caracterizada por orientarse al problema. De ahí que la defina como Techne des Problemdenkens, técnica del pensamiento de problemas o, como Díez-Picazo traduce entre nosotros, «técnica del pensamiento problemático». ${ }^{2}$ El punto de arranque es un problema concreto, una situación de la vida

${ }^{1}$ No es posible aquí, aunque sería sumamente ilustrativo, pararse en la evolución histórica de la tópica desde Aristóteles. Al respecto puede verse: BORNSCHEUER, L., Topik. Zur Struktur der gesellschaftlichen Einbildungskraft, Frankfurt/M, Suhrkamp, 1976, pp. 26-90; GIULIANI, A., Il concetto di prova. Contributo alla logica giuridica, Milán, Giuffrè, 1971; MARTIN, J., Antike Rhetorik. Technik und Methode, Munich, Beck, 1974.

${ }^{2}$ VIEHWEG, Th., Topik und Jurisprudenz, Munich, Beek, 5. a a ed. 1974 (La ed. 1953). Hay traducción castellana de la segunda edición alemana de 1963 a cargo de Luis Díez-Picazo Ponce de León (Tópica y Jurisprudencia, Madrid, Taurus, 1964, p. 49). En lo sucesivo citaremos esta obra por la quinta edición alemana y mediante las iniciales TJ, remitiéndonos entre paréntesis a la página correspondiente de la traducción española, cuando ésta exista, pues la edición por la que citamos finaliza con un apéndice (Anhang zur Fortentwicklung der Topik) que no cuenta con traducción, si bien en su versión alemana original fue publicado entre nosotros ya en 1973, bajo el título Zur zeigenössichen Fortentwicklung derjuristichen Topik («Anales de la Cátedra Francisco Suárez», 13/2, 1973, pp. 9-17). En varias ocasiones los términos de nuestra traducción del texto de Viehweg no se corresponderán exactamente con los de la mencionada edición castellana. En nuestro idioma, el más completo resumen de esta obra de Viehweg se contiene en RECASENS SICHES, L., Panorama del pensamiento jurídico en el siglo XX, vol. II, México, Porrúa, 1963, pp. 1.060-1.080. 
real, un estado de cosas que configura lo que Viehweg llama una «aporía». Una aporía significa, para Viehweg, una cuestión acuciante e ineludible, respecto de la que no está marcado un camino de salida (Weglosikeit), pero que no se puede soslayar. ${ }^{3}$ Y es esa cuestión la que desencadena un juego o intercambio de consideraciones que constituyen lo que propiamente se denomina «tópica o arte de la invención». ${ }^{4}$ Lo que la tópica pretende es dar orientaciones, indicaciones (Winke) de cómo proceder en una tal situación, a fin de no quedar bloqueado sin remisión. ${ }^{5}$

Viehweg define la noción de «problema» como «toda cuestión que aparentemente admite más de una respuesta y que necesariamente presupone una comprensión provisional, a partir de la cual aparece como cuestión a considerar seriamente y para la cual se busca precisamente una respuesta como solución». ${ }^{6}$

Delimitados en estos términos generales estos dos conceptos como base de la tópica, hay que preguntarse en qué radica la especificidad de los problemas jurídicos, en qué dimensión de lo jurídico se manifiesta ese carácter aporético que hace que sea el de la tópica el modo de pensar que conviene al trabajo con el derecho.

Sostiene Viehweg que la «aporía fundamental» de la «disciplina jurídica», ${ }^{7}$ lo que le da sentido y la hace necesaria, es la cuestión de «qué es lo justo aquí y ahora». Reconoce Vichweg que cada disciplina particular se constituye a partir del surgimiento de una determinada problemática. Lo peculiar de la Jurisprudencia como disciplina no estaría en esa circunstancia común de la existencia de una cierta problemática como punto de partida, sino en la permanencia del problema y en la cualidad epistemológica de los instrumentos que se emplean como respuesta o solución. En tal sentido, explica Viehweg que, mientras en unas disciplinas es posible hallar «proposiciones básicas» (Basissätze) seguras y realmente fecundas para su ámbito, lo que hace que tales disciplinas sean «sistematizables», otras aparecen como no susceptibles de sistematización, debido a que en su campo no cabe encontrar semejantes proposiciones básicas. Según Viehweg, «cuando esto ocurre sólo es posible una discusión de problemas. El problema central previamente dado se mantiene permanentemente, lo cual no es algo inhabitual en el ámbito de la acción humana. En esta situación -concluye- se encuentra claramente la Jurisprudencia». ${ }^{8}$

${ }^{3}$ TJ, p. 31 (trad. 49).

${ }^{4}$ TJ. p. 32 (trad. 50).

${ }^{5}$ TJ. p. 31 (trad. 49).

${ }^{6} \mathrm{TJ}$, p. $32(\operatorname{trad} .50)$.

${ }^{7}$ TJ, p. 96 (trad. 129). En este punto creemos que la traducción de la edición castellana no es del todo exacta, por lo que se recomienda su cotejo con el original alemán.

${ }^{8}$ TJ, p. 97 (trad. 129). 
Sentado esto, deriva Viehweg que es a partir de la tópica como se puede mostrar la estructura que conviene a la Jurisprudencia. Esta tesis general es desgranada en tres tesis derivadas: a) La estructura total de la Jurisprudencia sólo puede estar determinada desde el problema; b) los elementos constitutivos de la Jurisprudencia, sus conceptos y proposiciones, han de permanecer ligados de un modo específico al problema, y sólo a partir de éste pueden ser comprendidos; c) Tales conceptos y proposiciones sólo se pueden articular deductivamente en implicaciones que permanezcan próximas al problema. ${ }^{9}$

En suma, todo el edificio jurídico se explicaría en razón de la necesidad de resolver problemas, casos concretos. Pero a ello se suma, como circunstancia que confiere al trabajo con el derecho su impronta particular y lo hace desembocar en la tópica, el hecho de que nunca encuentra, con carácter definitivo, general e indiscutible, la respuesta al interrogante que ante cada caso se plantea: que sea lo justo aquí y ahora. Esa naturaleza discutible, «opinable», de todas las soluciones posibles sería el terreno abonado para el modo de proceder de la tópica. Ésta cifraría su aportación esencial en servir de vía para la propuesta de soluciones y de argumentos y base para el intercambio argumentativo de razones, con vistas al proceso que debe conducir a la decisión.

\section{2. Antisistematismo.}

Esa ligazón que Viehweg establece entre la concreción del problema y el modo de pensar de la disciplina jurídica que le tiene que dar respuesta, le lleva a una de las contraposiciones fundamentales de su teoría, esto es, entre Problemdenken y Systemdenken.

La raíz de la distinción entre estas dos formas de pensamiento, que Viehweg toma de Hartmann, ${ }^{10}$ está en función de que el punto de partida del razonamiento se sitúe en el problema o en el sistema. Si el acento se coloca en el problema, el proceso que conduce a la solución que para él se busca se desarrolla del siguiente modo: el problema, adecuadamente formulado, se inserta en un contexto deductivo previo, es decir, en un sistema estructurado con anterioridad, del cual se pretende extraer la respuesta. Por tanto, a efectos de su solución, el problema «se inordena en un sistema». Pero éste no determina mecánicamente y de modo autónomo la respuesta y el proceder que lleva a ella, sino que la prioridad del problema hace que la selección se realice desde la perspectiva dada por el propio problema: éste busca, en cierto modo, un sistema que coadyuve a la solución. ${ }^{11}$ Como explica Viehweg, «el planteamiento

${ }^{9}$ TJ, p. 97 (trad. 129-130).

${ }^{10}$ Cfr. HARTMANN, N., Diesseits von Idealismus und Realismus, en: HARTMANN, Kleine Schriften II, Berlín, De Gruyter. 1957. pp. 278-322. Vichweg cita esta obra de su publicación original en «Kant-Studien» 29/1924, pp. 163 ss, Para la crítica de la lectura de Hartmann que Viehweg lleva a cabo puede verse: CANARIS, C-W., Systemdenken und Systembegriff in der Jurisprudenz, Berlín, Duncker \& Humblot, 2. ${ }^{\mathrm{a}}$ ed. 1984, pp. 137-138, HORAK, F., Rationes decidendi. Entscheidungsbegründungen bei den älteren römischen Juristen bis Labeo, Aalen, Scientia, 1969, pp. 52-53.

${ }^{11}$ TJ. p. $33(\operatorname{trad} .51)$. 
del problema opera una selección del sistema y conduce habitualmente a una pluralidad de sistemas, sin que su compatibilidad sea probada desde un sistema omnicomprensivo». ${ }^{12}$

$\mathrm{Si}$, por el contrario, el punto de partida se pone en el sistema, se ofrece la siguiente perspectiva: «partiendo del sistema se opera una selección del problema». Sólo se admite el planteamiento de aquellos problemas que puedan encontrar solución dentro del sistema; el resto no se toman en consideración o se rechazan como problemas meramente aparentes. ${ }^{13}$

El rechazo por parte de Viehweg del pensamiento jurídico como Systemdenken se basa en una asimilación del concepto de sistema a la idea de sistema axiomático lógico-deductivo, considerado como prototipo del sistema perfecto. Así, dice que la tópica «presupone» que no existe un sistema deductivo y que «la constante vinculación al problema establece unos límites muy estrechos para la reducción y la deducción», permitiendo sólo encadenamientos de muy corto alcance, pues estos se deben interrumpir constantemente en atención al problema. ${ }^{14}$

Según Viehweg, un sistema deductivo exige «que toda proposición usada como premisa sea reconducida a otra y, finalmente, a una proposición central, o que, al revés sea derivada de ella $\mathrm{o}$, incluso, que sea ella misma establecida como proposición central». ${ }^{15} \mathrm{La}$ conformación más precisa del sistema deductivo sería la derivada del método axiomático, consistente en «la ordenación de, por una parte, los enunciados y, por otra, los conceptos de una rama (no lógica) cualquiera de acuerdo con su dependencia lógica». Para ello se han de encontrar los enunciados susceptibles de actuar como axiomas del sistema, de modo que de ellos puedan ser derivadas todas las demás proposiciones del mismo. Los requisitos que un sistema tal habrá de reunir son los de completud y compatibilidad e independencia de los axiomas. ${ }^{16}$

Entiende Viehweg que si se consigue establecer semejante sistema, poco campo de acción le queda a la tópica, ya que la deducción haría superflua la invención y el propio sistema asumiría la dirección del razonamiento. Todo lo más, la tópica jugaría algún papel en la elección de los axiomas. Con ello, las decisiones jurídicas se extraerían automáticamente del sistema mediante una simple deducción. ${ }^{17}$ Pero, según, Viehweg, un sistema de este tipo no es posible en el derecho. Su existencia exigiría poner cada rama jurídica bajo unos axiomas y conceptos fundamentales unitarios. Semejante sistema jurídico no se habría dado nunca,

12 Íbid.

13 Íbid.

${ }^{14}$ TJ, p. 44 (trad. 63).

${ }^{15}$ TJ. p. 43 (trad. 62).

${ }^{16}$ TJ. p. 82-83 (trad. 112-113).

${ }^{17}$ TJ, p. 44 (trad. 63). 
pero apostilla Viehweg que el pensamiento jurídico suele darlo como presupuesto. ${ }^{18}$

Es el carácter problemático de la Jurisprudencia, el papel directivo de su razonamiento que el problema asume, el que hace que un tal sistema no sea posible en el derecho. Un perfecto sistema lógico-deductivo en el ámbito jurídico exigiría: una estricta axiomatización del material jurídico; la rigurosa prohibición de interpretación dentro del sistema, lo cual sólo se logra plenamente mediante la introducción del cálculo; preceptos que fijen la interpretación de los hechos; la plena admisibilidad del non liquet, y la intervención continuada del legislador para regular con precisión sistemática los nuevos casos sobrevenidos. Y, aun así, puntualiza Viehweg, los axiomas mismos del sistema jurídico seguirían siendo arbitrarios desde el punto de vista lógico, de modo que en las operaciones intelectuales conducentes a su determinación permanecería un resto irreducible de pensamiento tópico. Con ello, la tópica seguiría determinando el aspecto más importante de todo el proceso, pues «los axiomas tienen que dar respuesta al problema de la justicia». ${ }^{19}$ Por tanto, serían los «problemas» los que pondrían en marcha el proceder sistemático. ${ }^{20}$

\subsection{Antilogicismo.}

Viehweg parte de la división del razonamiento jurídico o del operar con el derecho en dos momentos: uno, «prelógico», de búsqueda de premisas, y otro, propiamente «lógico», de conclusión a partir de aquellas premisas. La clave está en el peso que a uno y otro se atribuya. El segundo de ellos sólo tendría preponderancia metodológica si se pudiera partir en el derecho de un sistema normativo constituido y estable, articulado conforme a un esquema axiomático.

El tipo de ordenación o de «sistema» de los elementos centrales con que el razonamiento jurídico-práctico opera, los tópicos, no responde, según Viehweg, al esquema lógico-deductivo ni posee sus implicaciones prácticas: no hace que prevalezca el segundo de los momentos citados, la operación silogística, sino el primero, el de la búsqueda de premisas. La interrelación que existe entre los tópicos no se puede simplificar, en opinión de Viehweg, como interrelación meramente lógica. La formación de largas cadenas deductivas está reñida con la función de los topoi, y la constante vinculación al problema impide que la práctica con ellos se reduzca a meras operaciones lógicas, a razonamientos lineales. ${ }^{21}$

La inexistencia de un sistema jurídico lógico-deductivo conllevará, por tanto, la necesidad de poner el acento en el momento de la búsqueda de premisas. Estas premisas deben ser buscadas por cuanto que no vienen dadas por el sistema y, una vez halladas, determinan por completo

\footnotetext{
${ }^{18}$ TJ, p. 84-85 (trad. 114-116).

${ }^{19}$ TJ. p. 92 (trad. 123).

${ }^{20}$ TJ. p. 44 (trad. 63).

${ }^{21}$ TJ, p. 38-38 (trad. 57-58).
} 
la conclusión, el momento lógico. Según Viehweg, la tópica es, en cuanto ars inveniendi, el proceder adecuado para tal pesquisa de las premisas. Es más, la tópica se define precisamente como «un proceder de búsqueda de premisas». De este modo, la tópica es un tipo de «meditación prelógica», pues, en cuanto tarea, la inventio es primaria y la conclusio secundaria. La tópica debe mostrar primero cómo encontrar las premisas; la lógica las toma y trabaja con ellas. ${ }^{22}$ No se quiere decir, puntaliza Viehweg, que la lógica quede totalmente al margen del razonamiento jurídico, ni que la deducción no juegue ningún papel. La lógica desempeña un cometido esencial también aquí, pero no el principal, que es el de la inventio, desempeñado por la tópica. Como ya habría mostrado Cicerón, la tópica antecede a la lógica. ${ }^{23}$

\subsection{Función de los tópicos.}

¿De dónde extrae la tópica esas premisas con las que se opera el trabajo jurídico de solución de problemas? Conforme a la teoría de Viehweg, la función principal al respecto la realizan los topoi o tópicos. Afirma que cuando tropezamos con un problema procedemos de manera tal que tomamos, a modo de prueba, puntos de vista elegidos más o menos arbitrariamente. Mediante su ponderación se trata de obtener las premisas adecuadas al caso. Si hacemos este proceder objeto de una investigación atenta, veremos cómo determinados «puntos de vista directivos» encauzan la respectiva orientación. A esto lo llama Viehweg «tópica de primer grado». La pretensión de una mayor seguridad lleva a procurarse apoyo en «repertorios de puntos de vista», con lo que surgen «catálogos de tópicos». El proceder que los utiliza recibe la denominación de «tópica de segundo grado». ${ }^{24}$

La elección de los puntos de vista o tópicos que en cada caso se invocan no carece por completo de referencia regulativa o criterio selectivo, y la arbitrariedad y el desorden en la invocación de los tópicos existirían sólo dentro del conjunto de aquellos de tales que, a la luz del problema en cuestión, aparezcan como admisibles o pertinentes. Según Wiehweg, tanto los tópicos en particular como el tipo de interrelación que entre ellos se establece reciben su sentido del problema, y en atención al respectivo problema aparecen como adecuados o inadecuados. ${ }^{25}$

${ }^{22}$ TJ, p. 40 (trad. 58).

${ }^{23}$ Cfr. TJ, pp. 41, 91, 104 (trad. 58, 121-122, 136-137). También VIEHWEG, La «logique moderne du droit», «Arch. Phil. Dr.», 11/1966, p. 15; Rechtsphilosophie als Grundlagenforschung, "ARSP», 47/1961, p. 528. Dice Viehweg en este último trabajo que, en cuanto ciencia, la actual ciencia del derecho precisa del conocimiento de la ciencia lógica contemporánea, bajo su forma de lógica matemática, a fin de captar adecuadamente la estructura lógica de eso que se llama Jurisprudenz. Y añade que dar por sentado que su tipo de pensamiento no se puede presentar bajo la forma de un sistema deductivo no significa que falte todo género de interrelación ni que la lógica deductiva le sea totalmente ajena, sino, simplemente, que el «peso formal ha de radicar sobre otra forma de lógica, a saber, la lógica reductiva».

${ }^{24}$ TJ, p. 35 (trad. 53).

${ }^{25}$ TJ, p. 37-38 (trad. 55-57). 
El principal elemento definitorio de los tópicos en la doctrina de Viehweg es, por consiguiente, su función, el tipo de su utilidad en el razonamiento jurídico. Son elementos comunicativos que sirven a la argumentación. Su valor pragmático estriba precisamente en $\mathrm{su}$ indeterminación. ${ }^{26}$ La función de los tópicos es servir a la discusión de problemas, y su conocimiento supone la posesión de una especie de repertorio para facilitar la invención (une sorte de répertoire facilitant l'invention). ${ }^{27}$ Una vez que se plantea el problema, a cuya luz la invocación de los tópicos cobrará sentido, éstos funcionan como «posibilidades de orientación e hilos conductores del pensamiento». ${ }^{28}$ Los tópicos de que se disponga y que se invoquen o apliquen poseen relevancia no sólo para la solución del problema, sino incluso para su mismo entendimiento. Ello es así por cuanto que fijan y consolidan una cierta precomprensión, con independencia del hecho de que todo repertorio de tópicos es siempre elástico y susceptible de interpretación. ${ }^{29}$

1. 5. Algunas críticas.

La explicación por Viehweg de la tópica jurídica rara vez rebasa el nivel de generalidad e inconcreción que se manifiesta en la exposición precedente. De ahí que las críticas que se le suelen dirigir adolezcan con frecuencia de una cierta superficialidad. Y quizá por ello ha podido la tópica erigirse en concepto de moda en la doctrina y aparentar ser compatible con los más heterogéneos planteamientos teóricos. Por esa razón creemos que se impone sacar a la luz los presupuestos no siempre explícitos en la tópica jurídica y mostrar así cómo en el fondo de la misma subyace una muy determinada concepción del derecho y de su praxis, así como la adscripción a una moderna e innovadora orientación de la metodología jurídica. Pero antes, será de interés un primer acercamiento crítico a los tan generales planteamientos de Viehweg que acabamos de mostrar.

En primer lugar, la insistencia en el «problema» o la «aporía fundamental» da pie a que se pueda ver en sus tesis un punto de incoherencia o un contenido trivial. Si a las citadas nociones se les asigna una dimensión ontológica, como corresponde a la inspiración que respecto de ellas toma Viehweg de la fenomenología de Hartmann, ${ }^{30}$ nos encontramos con el dato chocante de que su pensamiento, marcadamente antiontologista

${ }^{26}$ VIEHWEG, Antirhetorische und rhetorische Kontrolle rechtlicher Argumentation, en: Estudios de Filosofía del Derecho y Ciencia Jurídica en Memoria y Homenaje al Catedrático Don Luis Legaz y Lacambra (1906-1980), vol. II, Madrid, Centro de Estudios Constitucionales, 1985, p. 850.

${ }^{27}$ TJ, p. 37 (trad. 55).

${ }^{28}$ TJ, p. 38 (trad. 56).

${ }^{29}$ TJ, p. 41-42 (trad. 60).

${ }^{30}$ Para la critica de la interpretación que hace Viehweg de estas nociones de Hartmann véase BLÜHDORN, J., Kritische Bemerkungen zu Theodor Viehwegs Schrift: Topik und Jurisprudenz, «Tijdschrift voor Rechtsgeschiedenis», 1970, pp. 1. 183-1.197. 
y declaradamente antimetafísico en muchas ocasiones, ${ }^{31}$ tendría en su mismo núcleo un apoyo con estos caracteres. Por contra, si las nociones mencionadas se privan de ese sentido «profundo», la doctrina parece abocada a erigir en pilar lo que no es sino una afirmación poco menos que banal y perfectamente evidente para cualquier doctrina que no quiera perderse en pura especulación gratuita: que mediante la práctica jurídica hay que resolver casos concretos dándoles la solución más justa posible, aun cuando el acuerdo sobre la justicia perfecta sea un ideal inalcanzable.

En segundo lugar, en lo que concierne a la postura antisistemática y antilogicista, se imponen también algunas puntualizaciones. La tópica jurídica parece afirmarse y querer perfilarse sobre la base de una serie de contraposiciones extremas y estrechamente emparentadas entre sí: la contraposición de las ciencias o disciplinas que poseen una base segura para predicar la verdad de sus tesis o axiomas, y aquellas otras en las que todo conocimiento no puede afirmarse más que como plausible; la contraposición entre el carácter de sistema axiomático que el tejido de conocimientos puede adoptar en las primeras, frente a la imposibilidad que en las segundas acontece de deducir conocimientos seguros o verdades ciertas de premisas siempre discutibles, con la consiguiente necesidad de justificación dialéctica de cualquier tesis que se pretenda defender; y la contraposición entre lógica, entendida como pura operación deductiva a partir de premisas firmes, y tópica o medio para sentar esas premisas.

Ante esto, la crítica puede poner de relieve que el contraste entre el modelo supuestamente «perfecto» de la ciencia natural o la matemática, y la índole del conocimiento en las ciencias sociales y las disciplinas de la razón práctica no es tan terminante, tal como se ha venido mostrando tras la crisis del modelo verificacionista de ciencia y en la discusión sobre la fundamentación de la matemática y los límites internos de los formalismos; que el esquema axiomático es un modelo de trabajo aceptable como banco de pruebas o auxilio lógico en una pluralidad de disciplinas, el derecho incluido, con independencia del grado de certeza de los enunciados que se coloquen como axiomas, y no reflejo de ningún tipo de inmutable estructura ontológica o de conocimientos, ${ }^{32}$ y que lógica y tópica, inferencia deductiva y discusión, no funcionan en la práctica como esquemas opuestos ni como patrones aplicables en una sucesión

${ }^{31}$ Véase, por ejemplo, TJ, p. 113-114.

${ }^{32}$ Para la adecuada consideración del concepto de sistema axiomático y de su alcance real puede verse en especial: ALCHOURRON, C.E./BULYGIN, E., Introducción a la metodología de las ciencias jurídicas y sociales, Buenos Aires, Astrea, 1974, pp. 86 ss.; OPALEK, K./WOLENSKI, J., Das Problem der Axiomatisierung des Rechts, en: WINKLER, G. (ed.), Rechistheorie und Rechtsinformatik, Viena/Nueva York, Springer, 1975, pp. 51-66; SAVIGNY, E. von, Zur Rolle der deduktivaxiomatischen Methode in der Rechtswissenschaft, en: JAHR, G/MAIHOFER, W. (ed.), Rechtstheorie, Frankfurt/M, Klostermann, 1971, pp. 315-351; RÖDIG, J., Axiomatisierbarkeit juristischer Systeme, en: RÖDIG, Schriften zur juristischen Logik, Berlín, Springer, 1980, pp. 65-90. 
cronológica. No se trata de que primero, mediante la tópica o cualquier otro procedimiento de invocación y discusión de argumentos, se fijen las premisas y, una vez establecidas, venga la lógica a extraer de ellas la conclusión. Lógica y tópica actuarían en continua imbricación, y al igual que no cabe en los ámbitos de lo opinable un pensamiento que trabaje sólo con deducciones, tampoco es viable una tópica que realice sus operaciones de propuesta o discusión de premisas al margen de los esquemas y las reglas de la lógica. La lógica es algo más que el esquema formal del silogismo final en que termina todo el complejo procedimiento razonador que conduce a decidir en uno u otro sentido.

Viehweg oscila a veces entre los términos radicales a que le conducen las antítesis que acabamos de mencionar, y una visión más matizada. De este modo, aun cuando rechace la viabilidad práctica del esquema axiomático-deductivo en el derecho, reconoce un lugar legítimo a la lógica en la labor jurídica, si bien, en cuanto que disciplina formal, subordinada al aporte material de la tópica. ${ }^{33} \mathrm{Y}$, aunque rechaza la configuración práctica del derecho como sistema axiomático perfecto, no deja de reconocer la utilidad ordenadora y didáctica de configuraciones más débiles del sistema. ${ }^{34}$ Pero con esto se comprueba que allí donde se sitúan los centros de rechazo por referencia a los cuales la tópica jurídica pretende delimitarse negativamente, esto es, al hablar de sistema axiomático y de mera deducción a partir de axiomas, se está rechazando un modelo cuya virtualidad real para la práctica jurídica nunca se ha afirmado en esos términos que se objetan. ${ }^{35} \mathrm{Y}$ en el momento en que, por entenderse los conceptos de lógica y de sistema más matizadamente, su incompatibilidad con el modelo de la tópica desaparece, deja de verse uno de los datos que prima facie parecían mostrar una línea de demarcación clara entre la tópica jurídica y otras propuestas metodológicas. Pues, si bien casi ninguna de éstas rechaza tajantemente la utilidad de la lógica y el sistema en el derecho, casi todas ellas ven esa utilidad limitada y precisada de complemento.

${ }^{33}$ Véase TJ, p. 91 (trad. 121-122). Para el interés original de Viehweg por la lógica puede verse su Die juristische Beispielsfälle in Leibnizens Ars combinatoria, en: SCHISCHKOFF, G. (ed.) Beiträge zur Leibniz-Forschung, Reutlingen, Gryphius, 1947, pp. 88-95.

${ }^{34}$ Véase, sobre lo que llama el «sistema didáctico», TJ, pp. 44 (trad. 63); sobre el «sistema tópico», Systemprobleme in Rechtsdogmatik und Rechtsforschung, en: Festschrift zum 150. jährigen Bestehen des Oberlandesgerichts Zweibrücken, Wiesbaden, Franz Steiner, 1969, pp. 337-338. Certeramente afirma ROBLES MORCHÓN que «La tópica no es contraria al sistema, sino al sistema cerrado» (Epistemología y Derecho, Madrid, Pirámide, 1982, p. 113).

${ }^{35} \mathrm{Ni}$ siquiera en la siempre citada Jurisprudencia de conceptos, ni en las más extremas formas de la teoría de la subsunción. Cfr. RÖDIG, J., Axiomatisierbarkeit juristicher Systeme, cit., p. 73, n. 23; FIEDLER, H., Zur logischen Konzeption der Rechtsfindung aus dem Gesetz und ihren historischen Bedingungen, en: Gesetzgebungstheorie, Juristische Logik, Zivil und Prozessrecht. Gedächtnisschrift für Jurgen Rödig, Berlin, Springer, 1978, pp. 130 ss. 
Por último, el concepto de topos adolece en esta doctrina de una gran heterogeneidad de descripciones y ejemplificaciones, y bajo él encajan desde puros lugares comunes de la vida ordinaria o principios de sentido común, hasta esquemas lógicos, fórmulas argumentativas, standards valorativos, principios generales del derecho e, inclusive, normas jurídicas positivas. ${ }^{36} \mathrm{El}$ hilo conductor común dentro de esta variedad desconcertante parecen estar en la nota de su funcionalidad para la argumentación jurídica. Tópicos parecen ser todos aquellos argumentos que en un contexto histórico, social y jurídico determinado cuentan a su favor con una presunción de plausibilidad y son tenidos como postulados evidentes o generalmente aceptados, de modo que no se discuten o, todo lo más, en caso de ser discutidos imponen la carga de la argumentación a quien los cuestione. Se integran en ese núcleo de premisas compartidas que hacen posible en cada sociedad la convivencia y la comunicación sobre una base común de entendimiento.

$\mathrm{Su}$ mayor problema es que en Viehweg y quienes desarrollan sus tesis no se establecen con claridad jerarquías entre los tópicos, o criterios para sentarlas. ${ }^{37}$ Se entiende que las partes en litigio disponen en cada caso de un arsenal de tópicos a invocar, pero, naturalmente, cada una traerá a colación aquellos que puedan funcionar como argumentos o razones en favor de su postura. Así, lo que acontece será una discusión de tópicos enfrentados e igualmente legitimados en ese sustrato social o jurídico de principios evidentes y opiniones consensuadas. Con ello queda sin resolver la pregunta acerca de los criterios dirimentes de la mayor o menor plausibilidad, racionalidad, fuerza o adecuación al caso de los tópicos en debate. También se ha dicho que la doctrina que elabora y propone con relevancia metódica la noción de topos no soluciona ninguno de los problemas metodológicos fundamentales, ya que respecto de los tópicos se plantearían iguales problemas de interpretación y subsunción que se presentan respecto de las normas jurídicas en la metodología jurídica tradicional. ${ }^{38}$

${ }^{36}$ Como tópicos jurídicos actuales cita Viehweg la buena fe, el interés, la protección de la confianza y los conceptos jurídicos en general (Cfr. TJ, pp. 95 -trad. 127-104 -trad. 137-). Críticamente respecto a la escasa ejemplificación de los tópicos de Viehweg, ENGISCH, K. Einführung in das juristische

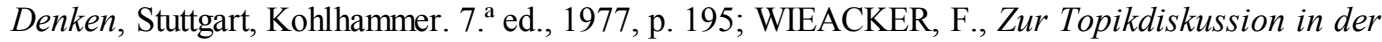
zeilgenössischen deutschen Rechtswissenschaft, en: Xenion, Festschrift für Pan J. Zepos, Atenas/Friburgo/Colonia, Katsikalis, 1973, pp. 395-396, n. 12. La más amplia enumeración de tópicos jurídicos se contiene en STRUCK, G. Topische Jurisprudenz, Frankfurt/M, Athenäum, 1971, pp. 20-34. Una exposición sistemática de los mismos puede verse en PERELMAN, CH., La lógica jurídica y la nueva retórica, Madrid, Civitas, 1979, pp. 120-128.

${ }^{37}$ En este sentido, por ejemplo, BOTTKE, W., Strafrechtswissenschaftliche Methodik und Systematik bei der Lehre von strajbefreienden und strafmildernden Täterverhalten, Ebelsbach, R. Greimer, 1979, p. 102-103; WEINBERGER, O., Topik und Plausibilitätsargumentation, «ARSP», 59/1973, p. 23; HORAK, F., Rationes decidendi, cit,, p. 54;ZIPPELIUS, R., Problemjurisprudenz und Topik, «Neue Juristische Wochenschrift», 1967, p. 2.232,

38 Así, BYDLINSKI, F., Juristische Methodenlehre und Rechtsbegriff, Viena/Nueva York, Springer, 1982, p. 148. 
No dejan de contenerse elementos pertinentes en las anteriores críticas. No obstante, buena parte de ellas perderán en relevancia o quedarán desenfocadas desde el momento que pasen al primer plano de consideración ciertos elementos teóricos cuya presencia en los escritos sobre la tópica jurídica no se muestra con la rotundidad y el efectismo de las algunas de las posturas que hemos reseñado, pero que no por ello dejan de ser los contenidos esenciales que dotan a tal doctrina de su mayor originalidad y profundidad. A estos aspectos dedicaremos las sucesivas consideraciones, y examinaremos la visión del derecho y del método jurídico que subyace a la tópica.

2. Tópica jurídica e idea del derecho.

En el centro de la discusión suscitada por las doctrinas de Viehweg y sus seguidores se sitúa, las más de las veces, el problema de cuál sea la relación entre la tópica jurídica y el principio de legalidad en la actuación del juez. Se trata de averiguar qué lugar ocupa el derecho positivo en el contexto de los tópicos que guían la obtención de decisiones jurídicas.

A la cuestión anterior se le han dado en la doctrina todo tipo de respuestas. Las posturas van desde quienes sostienen que la ley es un tópico más entre los otros, sin ningún tipo de estatuto superior, ${ }^{39}$ hasta los que rechazan la tópica jurídica precisamente porque, dicen, no reconoce el carácter vinculante de que la norma legal goza en todo proceso de obtención de decisiones jurídicas, ${ }^{40}$ pasando por quienes tratan de salvar la compatibilidad entre la doctrina metodológica de la tópica y el respeto al carácter preceptivo del derecho positivo. ${ }^{41}$

Sólo la determinación del concepto de derecho implícito en la doctrina de la tópica jurídica permitirá una respuesta más segura al interrogante reseñado.

Los críticos de Viehweg suelen citar la afirmación de éste de que «el pensamiento de problemas es reacio a las vinculaciones» como testimonio del rechazo de este autor al peso preponderante y vinculante de la ley positiva para la resolución de problemas jurídicos. ${ }^{42}$ Ahora bien, la tantas veces mentada afirmación de Viehweg ha de leerse en su contexto, a cuya luz se observará que no supone por sí misma un rechazo tan claro del principio de legalidad. No habla Viehweg aquí de vinculación

${ }^{39}$ SEIBERT, H-M., Fall, Regel und Topos, en: Rhetorische Rechtstheorie, Friburgo/Munich, Alber, 1982, pp. 321 ss.

${ }^{40}$ BYDLINSKE, F., Juristische Methodenlehre und Rechtsbegriff, cit., pp. 145-147; LARENZ, K., Metodología de la Ciencia del Derecho, Barcelona, Ariel, 2. ed., 1980, pp. 155-156; FLUME, W., Richter und Recht, Munich, Beck, 1967, pp. 29-30, 34; MÜLLER, F., Juristische Methodik, Berlín, Duncker \& Humblot, 2. ${ }^{a}$ ed., 1976, pp. 79-85.

${ }^{41}$ NOLL, P., Gesetzgebungslehre, Reinbeck bei Hamburg, Rowohit, 1973, p. 133, n. 159; BOKELOH, A., Der Beitrag der Topik zur Rechtsgewinnung, Diss.,Göttingen, 1973, pp. 51, 79, 83.

${ }^{42}$ Así, DIEDERICHSEN, U., Topisches und Systemalisches Denken in der Jurisprudenz, «Newe Juristische Wochenschrift», 1966, p. 703. 
legal, sino «lógica». ${ }^{43}$ Queda, pues, sin resolver la cuestión de cuál sea la función que las normas positivas desempeñan para la solución de problemas jurídicos. Únicamente se ha de considerar rechazada, por el momento, la teoría que sostenga que la aplicación del derecho es un puro silogismo a partir de premisas mayores normativas que determinan unívocamente la decisión.

Ante la falta en la obra de Viehweg de un tratamiento sistemático del papel de la ley positiva, y dado que habla con frecuencia de «derecho» o «ley» sin precisar el verdadero alcance de estos términos, se hace necesario inducir, a partir de sus textos, una cierta claridad sobre este aspecto.

En primer lugar, podemos poner de relieve que, frente a cualquier visión estática del derecho, Viehweg parece defender una concepción dinámica del mismo, entendiéndolo como actividad. Así se aprecia cuando afirma que en cada época la mayoría de los topoi de una disciplina están especificados, mientras que otros se pasan por alto, si bien éstos pueden ir ganando peso con el cambio de las situaciones y por vía de legislación e interpretación. Y añade: «una diligente y constante reedificación y ampliación del derecho, que cuida de que el andamiaje total de la actividad jurídica conserve su fijeza sin perder flexibilidad, forma el núcleo peculiar del arte del derecho». ${ }^{44}$ Es la constancia de la «aporía fundamental» de qué sea lo justo en cada caso la que hace ineludible ese carácter dinámico y adaptativo del derecho.

¿Qué función le corresponde al derecho positivo en un pensamiento jurídico así estructurado? La respuesta de Viehweg es que la trama pregunta-respuesta del pensamiento jurídico conduce a mostrar que el derecho positivo, en su función de respuesta, se ha de comprender como parte constitutiva de la búsqueda del derecho (Rechtssuchen). El único elemento en que se basa la unidad del derecho se sitúa en la aporía fundamental, en ninguna otra parte. ${ }^{45}$ Un pensamiento jurídico que entienda como su misión el hallazgo de lo que sea en cada caso lo justo en situaciones distintas, debe contar con la posibilidad de renovar su posición respecto de tal aporía fundamental, esto es, tiene que ser «móvil». Ello no cuadra con una estructura conceptual y de enunciados que trate de fijar las soluciones de una vez para siempre y que pretenda dar lugar a encadenamientos deductivos para alcanzar la resolución de cada nuevo caso. Más bien habrá de recurrir el pensamiento jurídico, debido a la inabarcabilidad de las situaciones problemáticas posibles, a una pluralidad

${ }^{43}$ Véase TJ, p. 41 (trad. 59-60).

${ }^{44}$ TJ, p. 95 (trad. 127).

${ }^{45}$ TJ, p. 100: «En tanto el problema fundamental conserva su lugar primigenio y constante, resulta para el derecho positivo y para todo lo que esté en relación con él una referencia mediata o inmediata a este problema. Queda visible que todas las partes constitutivas de la búsqueda del derecho deben permanecer necesariamente dependientes y que por ello no es lícito el intento de desligarlas del fundamento problemático, para, a continuación, ordenarlas en sí mismas de modo aislado». 
asistemática de puntos de vista, que no son principios fundamentales pertenecientes a un pensamiento deductivo, sino tópicos, reglas directivas. ${ }^{46}$ Viehweg no llega a sostener expresamente que la ley positiva no sea sino un tópico más entre los muchos que concurren para la obtención de la decisión jurídica. Pero muchas de sus afirmaciones parecen traslucir esta idea, como cuando dice que la ley no es más que una de las partes de la búsqueda del derecho. Y es que tal búsqueda tendría carácter constitutivo del propio derecho, del objeto que se busca. No es este algo que venga dado de antemano y que se averigüe para aplicarlo tal como existe y se nos aparece (en forma de norma positiva, por ejemplo), sino algo que se está creando mediante el propio acto de búsqueda de solución para cada concreto problema. Y esta creación se realiza a partir de una serie de elementos auxiliares que son puntos de vista o argumentos, es decir, tópicos. Uno de ellos sería el derecho positivo aplicable.

Hemos de interrogarnos acerca de si para Viehweg la ley supone para la resolución de casos un tópico al mismo nivel que los otros o si posee un rango superior y predominante. Una primera dificultad de la comparación, que muestra cómo para Viehweg la determinación de lo jurídico no se realiza al margen de la ley, sino más allá de la ley, es que, para él, el derecho positivo no es algo que se coloque al lado de los elementos que aporta la tópica, ya sea en pie de igualdad o de superioridad, sino que los mismos textos jurídicos están sometidos en buena parte a la acción y el imperio de la tópica, pues se puede fijar un texto de una vez por todas, pero no es así su sentido, que es lo que en definitiva importa. ${ }^{47}$

Viehweg no defiende nunca una aplicación contra legen de los tópicos (de los tópicos distintos de la ley, se entiende). El texto legal sería, siempre que exista, el topos de partida. Pero por su generalidad, la rigidez de su forma y su textura abierta, precisa ser concretado mediante otros tópicos que determinen sus sentidos posibles y hagan viable la discusión tendente a obtener el significado que mejor se adecue a la realidad de cada caso a resolver. La tópica regiría esa discusión y proporcionaría los argumentos en litigio. El derecho propiamente dicho se constituiría en ese proceso dialógico, y no se identificaría exclusivamente con el punto de partida del mismo (el derecho positivo, cuando exista, o los tópicos particulares que se invoquen), sino con su elemento resultante: las soluciones de los casos jurídicos. Bien entendido que derecho será la solución de cada caso, pero nunca la suma de las soluciones dadas a los casos, pues esto formaría un nuevo corpus de textos «legales», un nuevo «sistema» con las mismas insuficiencias. El derecho constituye una realidad dinámica y en permanente estado de conformación.

4647 Sobre la interpretación, como actividad adaptadora y configuradora del material normativo, marcada por la tópica, TJ, p. 54-55 (trad. 76) VIEJINVEG, Rechtswissenschaftliche Grundiagenforschung und zeitgenössische Rhetorik, en: Estudios en honor del doctor Luis Recaséns Siches, vol. 1, México, UNAM, 1980, p. 943.

${ }^{47}$ Sobre la interpretación, como actividad adaptadora y configuradora del material normativo, marcada por la tópica, TJ, p. 54-55 (trad. 76) VIEJINVEG, Rechtswissenschaftliche Grundiagenforschung und zeitgenössische Rhetorik, en: Estudios en honor del doctor Luis Recaséns Siches, vol. 1, México, UNAM, 1980, p. 943. 
Si alguien invoca aquí el carácter lesivo de esta construcción para el principio de legalidad o la seguridad jurídica, la réplica podrá ser distinta según que la tópica jurídica se entienda como descripción o como propuesta normativa. Si se entiende, en este último sentido, que las afirmaciones de Viehweg se presentan con carácter programático, con la pretensión de regir la práctica jurídica y de que ésta se adapte a sus directrices, cabría plantearse si no se debería buscar un modelo que funcione con más respeto del principio de legalidad. Pero si, como parece más razonable pensar, las tesis de Viehweg se plantean como descripciones de lo que realmente acontece en dicha práctica, entonces no tendrá sentido rechazarlas so pretexto del deber de un más fiel acatamiento del principio de legalidad, pues malamente se puede rebatir un enunciado descriptivo mediante una proposición de deber ser o una formulación de deseos. En este caso, la posible crítica de las doctrinas de Viehweg sólo podría venir por el lado de su contrastación con la realidad, para comprobar si la práctica jurídica y el uso de los textos legales son realmente como él los describe. Pero esta labor empírica y ejemplificativa, prácticamente ausente por completo de los trabajos de Viehweg, constituye seguramente una de las más notorias lagunas de toda la metodología continental, y sólo parcialmente comienza a ser colmada en el marco del estudio de la argumentación jurídica práctica o de ciertos estudios sociológicos sobre el derecho y la praxis de su aplicación ${ }^{48}$.

\section{Tópica y método jurídico.}

¿Considera Viehweg la tópica como un método? Deja claro que en su concepción la tópica no puede ser concebida como método jurídico. Ahora bien, ¿qué entiende Viehweg por «método»? Para él, método, en sentido propio, sólo es aquel proceder que sea estrictamente revisable con medios lógicos y dé lugar, por tanto, a un perfecto sistema deductivo $^{49}$. Para que el proceder jurídico que la tópica impregna se transformara en método, sería necesario, según Viehweg, que sistema deductivo y subsunción pasaran a primer plano y lograran preeminencia. Solamente así cobraría entidad científica el trabajo jurídico ${ }^{50}$. Vemos, pues, que Viehweg niega a la tópica la condición de método jurídico basándose en una muy estrecha concepción de lo que se ha de llamar método, concepción vinculada al más puro positivismo y apenas vigente en los tiempos actuales ${ }^{51}$.

\footnotetext{
${ }^{48}$ Sobre esta labor necesario Cfr. NEUMANN, U., Juristische Argumentationslehre, Darmstadt, Wissenschaftliche Buchgesellschaft, 1986, p. 118.

49 TJ, p. 76 (trad. 105).

${ }^{50}$ TJ, p. 91 (trad. 122).

${ }^{51}$ Wieacker destaca que Viehweg niega a la tópica la cualidad de método porque reserva este concepto para el proceder deductivo y el pensamiento sistemático (WIEACKER, F., Ueber strengere und unstrenge Verfahren der Rechtsfindung, en: Im Dienst
} 
Si empleamos un concepto de método menos restrictivo, la anterior posición de Viehweg no nos impedirá tomar conciencia del significado metodológico de la tópica y del papel que vino a desempeñar a este respecto en el contexto de las doctrinas de nuestro tiempo.

Por método se entiende, en consonancia con la etimología del término, la vía a seguir para alcanzar una meta, un resultado correcto ${ }^{52}$. Se dice que esa vía consiste en una serie de indicaciones para la solución de problemas $^{53}$; o en el conjunto de los procedimientos intelectuales requeridos para llevar una investigación al fin deseado ${ }^{54}$; o en «una serie de operaciones-tipo dispuestas en razón de un cierto resultado» ${ }^{55}$, etc. Y la metodología será «la disciplina que se ocupa de los métodos» ${ }^{56}$, «la doctrina de los caminos que conducen hacia la meta final del trabajo científico ${ }^{57}$. En cuanto a la finalidad del método jurídico, parece existir un acuerdo generalizado en las doctrinas modernas que consiste en eliminar la arbitrariedad de la práctica jurídica y conseguir el mayor grado posible de racionalidad de la misma ${ }^{58}$.

Por otra parte, las doctrinas sobre el método nunca pueden entenderse desvinculadas del concepto de derecho, tácito o expreso, sobre el que se asientan. Cabe establecer una distinción de base dentro de la doctrina a partir de la consideración de tres aspectos inescindiblemente unidos: la noción de derecho, la idea de racionalidad (o corrección, o verdad, según las terminologías) en el trabajo jurídico, y las reglas o indicaciones metódicas.

Lo que podemos llamar la teoría tradicional del positivismo legalista y/o científico-jurídico ${ }^{59}$, tal como ha sido defendida en el plano teórico

and Recht und Staat, Festschrift für Werner Weber zum 70. Geburtstag, Berlín, Duncker \& Humblot, 1974 p., 441, n. 60. Al respecto también, HERNÁNDEZ GIL, A., La ciencia jurídica tradicional y su transformación, Madrid, Civitas, 1981, p. 97; GIL CREMADES, J. J., La motivación de las decisiones jurídicas, en: Estudios en honor del Doctor Luis Recaséns Siches, cit., p. 415.

${ }^{52}$ FIKENTSCHER, W., Methoden des Rechts, I, Tübingen, Mohr, 1975, p. 22.

${ }^{53}$ DUBISCHAR, R., Vorstudien zur Rechtswissenschaft, Stuttgart, Kohlhammer, 1974, p. 33.

${ }^{54}$ BOBBIO, N., Voz, «Método», en: Novissimo Digesto Italiano, vol. X, Turín, UTET, 1964, p. 602.

${ }^{55}$ SCARPELLI, U., Il metodo giuridico, en GUASTINI, R. (ed.), Problemi di teoria del diritto, Bolonia, Il Mulino, 1980, p. 261.

${ }^{56}$ Ibid., p. 262.

${ }^{57}$ HECK, Ph., Begriffsbildung und Interessenjurisprudenz, ed. de R. Dubischar, Bad Homburg, Gehlen, 1968, p. 146.

${ }^{58}$ Véase, por ejemplo, KRIELE, M., Theorie der Rechtsgewinnung, Berlín, Duncker \& Humblot,

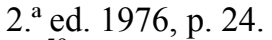

${ }^{59}$ Sobre el alcance de las expresiones «positivismo legalista» y «positivismo científico-jurídico» cfr. WIEACKER, F., Privatrechtsgeschichte der Neuzeit, Göttingen, Vandenhoeck \& Ruprecht, 2. ${ }^{\text {ed. }}$., 1972, p. 431-432. 
principalmente en el siglo XIX, y tal como parece imperar aún hoy en la conciencia de muchos juristas y en la práctica docente de muchas Facultades de Derecho, se apoya en una visión del derecho como sistema preferentemente estático, cerrado y completo o, al menos, autosuficiente como ordenamiento normativo para dar solución a toda cuestión nueva. Consiguientemente, el tipo de racionalidad que preside la tarea del jurista será la racionalidad interna del sistema. Será la racionalidad del derecho mismo como dato, como resultado preestablecido, la que asegurará la racionalidad del producto de su aplicación, de las decisiones de los casos. De ahí se sigue también que lo que para esta orientación se concibe como metodología jurídica será mera descripción de los pasos formales del razonamiento por el que, de lo racionalmente dado con carácter general, se extraen nuevos contenidos racionales para los casos concretos, exposición del armazón lógico-deductivo de la aplicación de las normas y, todo lo más, de los instrumentos normativos que en los ordenamientos o en el bagaje tradicional del jurista se prevén para determinar de modo seguro y suficiente la interpretación e integración de las normas. La aplicación del derecho sería, ante todo, un acto de conocimiento, guiado por las pautas metodológicas, y se entenderá, consecuentemente, que la metodología jurídica es, antes que nada, «metodología de la ciencia del derecho».

Por contra, para lo que grosso modo podemos llamar las directrices metodológicas antilegalistas, de las que la tópica jurídica, con las matizaciones que hemos señalado, forma parte, el derecho reviste un carácter dinámico y abierto se halla en trance de permanente recreación y sólo de modo imperfecto o aproximativo es posible hablar de sistema. La norma deja su papel preferente al caso o problema a resolver. El centro de mira pasarán a ocuparlo las decisiones de esos casos, en cuanto opciones entre alternativas decisorias diversas e igualmente posibles, compatibles con el derecho preestablecido en el ordenamiento normativo. El tipo de racionalidad que en lo posible ha de ser garantizado ya no será la determinada por ningún género de «lógica» interna del sistema normativo, sino que habrá de buscarse en instancias externas a éste, ya se trate de la conciencia del juez, del consenso social, de ciertas reglas argumentativas, etc. Las pautas metódicas que se traten de fijar como guía para la obtención de las decisiones jurídicas serán reglas de la razón práctica, orientaciones dirigidas a mostrar y/o reglamentar el uso que el jurista hace del margen de libertad que para la decisión le dejan ciertos caracteres estructurales del ordenamiento positivo (lagunas, contradicciones, equivocidad del lenguaje, etc.). La solución de casos o conflictos particulares en sede jurídica significa, para estas doctrinas, un mecanismo de «obtención» del derecho por vía decisoria, debiendo asegurarse el mayor nivel posible de racionalidad de la decisión, de racionalidad práctica, mediante ciertas reglas metódicas o argumentativas. Estas serán reglas del razonar jurídico práctico, no, como en el caso anterior, reglas de conocimiento del método científico.

El siguiente cuadro ilustra estas diferencias entre esas dos perspectivas generales. 


$\begin{array}{lllll} & \text { Idea del } d . & \text { Racionalidad } & \text { Método } & \text { Calific. praxis } \\ \text { Positivismo } & \text { Estático, } & \text { Interna, } & \text { Lógico- } & \text { Conocimiento } \\ & \text { cerrado } & \text { lógica } & \text { deductivo } & \text { científico } \\ \text { Corrientes } & \text { Dinámico, } & \text { Externa } & \text { Razón } & \text { Decisión, } \\ \text { antilegalistas } & \text { abierto } & \text { a sistema } & \text { práctica } & \text { valoración }\end{array}$

Simplificando, se puede sostener que cuanto mayor es el grado de racionalidad que se atribuye al derecho, menor significado se asignará al proceso decisorio y a la decisión misma; y a la inversa. Así, el positivismo legalista concebirá el derecho como sistema racional perfecto, y su aplicación como ejecución de un sencillo silogismo, por medio del cual es hallada la solución del caso. Frente a ello, para aquellas doctrinas, como la de la tópica, que no consideran el derecho como sistema perfecto y plenamente racional en cuanto dado, como necesitado de constante complemento y dependiente de otros factores externos a él, la actividad de quienes lo «aplican» será crucial y se ha de procurar garantizar su racionalidad.

En este marco general de las más modernas direcciones metodológicas, es posible una cabal comprensión del alcance de la tópica jurídica, tal como Viehweg la propugna. Lo que Viehweg anticipa, en la misma época en que lo hacen también otros autores con matices diversos, es la perspectiva argumentativa ${ }^{60}$, la idea de que es en el contexto de cada situación donde se ponen las bases para la decisión correcta, a través del intercambio de razones. Y los propios contornos de la situación se expresan mediante la acción comunicativa entre sujetos. Se trataría en todo ello de un proceso retórico, marcado por la inexistencia de verdades apodícticas que puedan fundar una solución indiscutible, y abocado, por tanto, a la permanente construcción y reconstrucción de soluciones meramente plausibles. Y la tópica sería el auxilio principal del que las partes en ese proceso dialógico pueden servirse como fuente de sus argumentos, de esas razones sobre cuya discusión se asentará la decisión.

En Vichweg, la clave para la racionalidad de la decisión no habrá de buscarse simplemente en la conclusión que pone fin al razonamiento, sino en el propio proceso razonador; y ya que las premisas de este razonamiento no vienen dadas como perfectamente seguras por ningún sistema previo, su conveniencia será mostrada por su expresa fundamentación argumentativa en el proceso que conduce a la decisión. Tanto como los contenidos, cuenta para la racionalidad de la decisión final la índole del mecanismo argumentativo y procedimental que lleva a ella y la fundamenta. Cuando es precisamente el contenido de la decisión lo que es objeto de disputa, el respaldo máximo que aquélla puede pretender radica en la aceptación por los litigantes o por el medio en general, sentado que no existe una fuente que imponga por sí sola contenidos para la decisión. Y la única manera de que tal reconocimiento pueda tener lugar

${ }^{60}$ En el mismo sentido, para el encuadre de la teoría de Viehweg, NEUMANN, U., Juristische Argumentationslehre, cit., p. 54. 
de modo que quepa llamarlo racional, es arbitrando un procedimiento argumentativo en el que las partes expresen con libertad sus argumentos y contraargumentos.

3. 1. Tópica, retórica y pragmática.

Distingue Viehweg entre argumentación primaria y secundaria. La secundaria consistirá en la pura inferencia lógica de la decisión, una vez que se han fijado todas las premisas necesarias. De esta argumentación se ocuparía la lógica. Pero previamente acontece la argumentación primaria, que constituye el ámbito en que esas premisas han de quedar fijadas. Este ya no sería campo de la lógica, sino de una teoría retórica evolucionada ${ }^{61}$.

La retórica sería competente para constituirse en teoría de la argumentación jurídica, por cuanto que esta argumentación transcurre en la forma de un diálogo, de un intercambio comunicativo (Reden und Unterreden). La retórica, según Viehweg, se pregunta precisamente por lo que ha de ser el recíproco comportamiento correcto de los dialogantes. Opina que con los planteamientos de la retórica es posible dar cuenta de cuáles son las reglas que los partícipes en la argumentación tienen que respetar para que su diálogo y los resultados de él dimanantes puedan considerarse verdaderamente fundamentados y ser objeto de reconocimiento. Existirían ciertos postulados de toda discusión racional, entre los que destacan determinadas obligaciones comunicativas que los dialogantes han de asumir, de modo que no cabe hablar de una fundamentación suficiente cuando no se respetan esos principios argumentativos ${ }^{62}$.

¿Cuáles son esos postulados o en qué consisten concretamente esas obligaciones que se han de salvaguardar en la discusión racional? Aquí sería fácil asociar esos planteamientos tan generales con la pragmática trascendental de Apel y ver en tales postulados la expresión de premisas pragmático-trascendentales de toda justificación, configurando la estructura a priori de la ética comunicativa y de toda actuación social que se oriente a la racionalidad y no a la imposición abusiva y el uso de la fuerza; o con la pragmática universal de Habermas, para quien la interacción social es primariamente interrelación comunicativa, y toda interacción que se pretenda racional y liberada de ataduras irracionales (uso de la fuerza, manipulación, intereses egoístas, etc.) se ha de orientar a las reglas que definen la situación discursiva ideal en que sería posible un consenso auténtico sobre base racional; o con el constructivismo de la Escuela de Erlangen, a tenor del cual es posible reconstruir por vía

${ }^{61}$ Cfr. VIEHWEG, Historische Perspektiven der juristichen Argumentation: Il Neuzeit, «ARSP», Beiheft NF. 7, 1972, p. 71-72; Positivismus und Jurisprudenz, en: BLÜHDORN, J./RITTER, J. (ed.), Positivismuns im 19. Jahrhundert, Frankfurt/M, Klostermann, 1971, p. 110; Was heisst Rechtspositivismus?, en: SCHNEIDER, P./SAAME, O. (eds.), Positivismus als wissenschaftstheoretisches Problem, Mainzer Universitätsgespräche, WS 1964-65, Mainz, 1968, p. 17; Que veut-on dire parpositivisme juridique?, «Arch. Phil. Dr.», 10/1965, p. 187.

${ }^{62}$ Cfr. VIEHWEG, Notizen zu einer rhetorischen Argumentationstheorie der Rechtsdisziplin, «Jhb. RSoz. Rth», 2/1972, p. 92-93. 
dialógica y consensual las reglas del actuar práctico, a partir de la elaboración ex novo de un lenguaje cuya lógica interna sin fisuras posibilite el entendimiento y el acuerdo racional. Las afirmaciones pragmáticas de Viehweg son compatibles también con los recientes intentos de definir, sobre la base ecléctica de las teorías citadas y otras, las condiciones para el ejercicio racional de la razón práctica en la argumentación conducente a la decisión jurídica, como en el caso de la Theorie der juristischen Argumentation de Alexy; o con la enunciación de los recursos retóricos disponibles para la argumentación no demostrativa y de su lógica peculiar, tal como se señalan en la «Nueva Retórica» de Perelman.

Ahora bien, Viehweg no concreta mucho más sus afirmaciones. Simplemente añade, como requisito de una teoría de la argumentación jurídica racional, la exigencia de que se considere prioritariamente el aspecto pragmático y situativo de toda argumentación jurídica. Más que la situación de los signos en el discurso, lo que importaría a la hora de definir las condiciones de una argumentación jurídica racional es tomar en cuenta la situación de los sujetos en el contexto que preside su comunicación. La posición del sujeto condiciona su actuar comunicativo. Sólo a partir de la conciencia del carácter eminentemente «situativo» de la argumentación jurídica podrá verse ésta en su auténtica función. Esta función no es otra que la de servir de vehículo para hallar y fundamentar la solución de un problema práctico, del que arrancan y al que se remiten todas las consideraciones que interesan ${ }^{63}$.

Para Viehweg, se trataría de desarrollar un «modelo retórico de argumentación», en el que se conciba toda argumentación como discurso fundamentador, y el discurso como actividad comunicativa que contiene obligaciones comunicativas. La retórica proporcionaría el más apto instrumento de análisis del proceder argumentativo, poniendo de manifiesto la dependencia contextual de toda argumentación y el modo cómo en ella se entrecruzan la dimensión tópica y la dimensión ética. La retórica puede mostrar la clave última de la argumentación porque, en palabras de Viehweg, «la argumentación tiene su última ratio en el método del argumentar ${ }^{64}$. La retórica muestra el modo de hacer comprensible el discurso a partir de la dimensión pragmática del uso del lenguaje, dimensión en la cual éste no cumple una tarea puramente descriptiva, sino también directiva ${ }^{65}$.

«La situación discursiva -dice Viehweg- se ha de explicar básicamente como situación comunicativa». Lo que en ésta se desarrolla es «una

${ }^{63}$ TJ, p. 111 ss, VIEHWEG, Rechtswissenschaftliche Grundlagenforschung und zeitgenössische Rhetorik, cit., p. 940 ss.

${ }^{64}$ VIEHWEG, Notizen zu einer rhetorischen Argumentationstheorie der Rechtsdisziplin, cit., p. 445 ss; Historische Perspektiven der juristischen Argumentation, cit., p, 72.

${ }^{65}$ VIEHWEG, Schritte zu einer rhetorischen Rechtstheorie, en: Kultur, Kriminatität und Strafrecht. Festschrift für Th. Würtenberger, Berlín, Duncker \& Humblot, 1978, p. 7. 
trama directiva para el entendimiento a partir de recíprocas propuestas, indicaciones, aceptaciones, etc.» Es decir, el discurso jurídico se puede comprender y analizar a partir de la situación o marco que entre los propios interlocutores se define para el mismo mediante la aceptación de premisas, presupuestos compartidos, fijaciones semánticas, intereses en pugna, argumentos en juego, etc. Dados estos márgenes flexibles dentro de los que el discurso jurídico se mueve y cobra en cada caso su sentido, la retórica se encarga de poner de manifiesto la dimensión creativa de dicho discurso, frente a la fijación de otros enfoques en los aspectos sintácticos o semánticos exclusivamente ${ }^{66}$.

¿Qué significado posee la tópica para este análisis retórico? La tópica sería núcleo central de la retórica. Si ésta investiga el proceso comunicativo mediante el cual en la «situación discursiva» se establecen significados, la tópica ofrece la mejor perspectiva para la comprensión de ese proceso productivo, pues los tópicos proporcionan «auxilios para la invención», son una fuente de argumentos posibles, cuya utilidad se examina en cada caso a la vista de la concreta situación ${ }^{67}$. Serían una especie de moldes diversamente utilizables en atención a las circunstancias que definen cada argumentación. Esta función pragmática de los tópicos privaría de relevancia a la constatación de que, desde el punto de vista sintáctico, aparecen como carentes de un orden lógico, y, desde el punto de vista semántico, como excesivamente vagos ${ }^{68}$.

¿Cómo se actualiza la retórica clásica para poder rendir fruto como teoría de la argumentación jurídica? La respuesta de Viehweg es que ha de incorporar, ante todo, los nuevos hallazgos de la semiótica y de las teorías de la comunicación ${ }^{69}$. Añade que en los últimos tiempos se han desarrollado una serie de teorías que ayudan a comprender mejor ese proceso argumentativo regido por la retórica, teorías pertenecientes a disciplinas como la lógica (la lógica dialógica de Lorenzen y Kamlah), la lingüística (ante todo, los desarrollos de la pragmática) y la ética (la ética del discurso) ${ }^{70}$.

Sin embargo, a pesar de estas direcciones que apunta, no concreta más Viehweg sus propuestas, ni precisa más esas reglas de índole retórica que han de gobernar la racionalidad del argumentar jurídico. De ahí que haya podido decirse que no es la suya una auténtica y completa teoría de la argumentación jurídica ${ }^{71}$. Define su idea de la racionalidad

${ }^{66}$ Ibid. p. 6.

${ }^{67}$ Ibid.; VIEHWEG, Rhetorik, Sprachpragmatik, Rechstheorie, en: Recht und Gesellschaft. Fesischrift für Helmut Schetsky, Berlín, Duncker \& Humblot 1978, p. 719-720.

${ }^{68}$ Scritte zu einer rhetorischen Rechtstheorie, cit., p. 6.

${ }^{69}$ Ibid., p. 7.

${ }^{70}$ TJ., p. 116-119.

${ }^{71}$ Véase DREIER, R., Zur Problematik und Situation der Verfassungsinterpretation, en: DREIER, R./SCHWEGMANN, F. (ed.), Probleme der Verfassungsinterpretation, 
de la argumentación jurídica afirmando que «la racionalidad de la Jurisprudencia debe consistir al menos en una óptima discutibilidad ${ }^{72}$. Lo que no explica es cómo se reglamenta tal discutibilidad, o cuándo se puede tener por alcanzado dicho grado óptimo.

\section{2. Tópica y consenso.}

Cabe pensar, y así se ha sostenido a veces ${ }^{73}$, que la tópica jurídica desemboca en la defensa de un criterio consensualista como solución del interrogante metodológico último. La pregunta sería ¿se puede entender que la tópica sitúa en el consenso el criterio determinante de la racionalidad de las decisiones jurídicas?

Se hace necesario distinguir dos ámbitos, relativos ambos al proceso decisorio, en los que el consenso puede actuar como elemento determinante: la selección de las premisas, de los argumentos que pueden fundar las soluciones posibles, por un lado, y, por otro, la decisión misma, como opción concreta basada en la elección de una de esas soluciones admisibles y de los argumentos que pueden apoyar ésa y no otra de las soluciones en disputa. Comprobaremos cómo el eje central de actuación del consenso en este proceso decisorio es, para la doctrina tópica, el primero de esos ámbitos citados, mientras que no queda claro qué tipo de criterio puede velar por la racionalidad de la elección en el segundo ámbito.

Dice Viehweg que lo decisivo es «una especial elección de premisas que se sigue de un determinado modo de entender el derecho a la vista de la aporía fundamental» ${ }^{74}$. Esta elección de premisas sería la que tiene lugar con arreglo al modelo tópico, y aquí es donde el consenso desempeña en la teoría de Viehweg una función decisiva, precisamente para la selección de los tópicos que funcionan como argumentos o premisas posibles y a partir de los cuales se alcanzará la solución.

Con anterioridad incluso al proceso propiamente discursivo de selección de argumentos, existiría un primer elemento que podemos llamar consensual y que tiene que ver con la necesaria participación de los interlocutores en lo que cabe denominar, mostrando un elemento de conexión con la filosofía hermenéutica, un común horizonte hermenéutico. De ahí, según Viehweg, que, aun cuando el modo de pensar tópico sea esquivo a las vinculaciones, no pueda prescindir por completo de ellas, pues nadie puede llevar a cabo una prueba convincente sin lograr mantener con su interlocutor, cuando menos, un círculo acotado por un entendimiento común. Los tópicos serían importantes para edificar y fijar

Baden-Baden, Nomos, 1976, p. 28; en el mismo sentido, HASSEMER, W., Juristische Argumentationstheorie und juristische Didaktik, «JHB. Rsoz. Rth.», 2/1972, p. 47.

${ }^{72}$ VIEHWEG, Zwei Rechtsdogmatiken, en: Philosophie und Recht. Festschrift für C.A. Emge, Wiesbaden, Franz Steiner, 1960, p. 114.

${ }^{73} \mathrm{Y}$ así se ha entendido a veces: VOGEL, K., Der räumliche Anwendungsbereich der Verwaltungsrechtsnorm, Frankfurt/M., Metzner, 1965, p. 364.

${ }^{74}$ TJ, p. 104 (trad. 62-63) 
ese entendimiento, pues, en palabras de Viehweg, «desenvuelven las preguntas y las respuestas adecuadamente e indican qué es lo que parece digno de una reflexión más profunda. Tiene lugar así -añade- de una manera continua, un acuerdo recíproco. Los tópicos, tanto especiales como generales, son muy apropiados para mostrar la dimensión dentro de la cual uno se mueve sin poderla abandonar, si no quiere perder ese entendimiento que hace posible la prueba» ${ }^{75}$.

En lo que propiamente se refiere al consenso sobre las premisas, sostiene Viehweg que en el procedimiento descrito las premisas fundamentales se legitiman «mediante la aceptación del interlocutor». Se tiene por evidente aquello que no es objeto de discusión, y sobre esta base las premisas se consideran relevantes o irrelevantes, admisibles o inadmisibles, etc. La discusión es aquí «la única instancia de control». «Lo que en la disputa se justifica mediante la aceptación es admitido como premisa», dice Viehweg. Como garantía de que como tal no se admitirá algo irrazonable menciona la circunstancia de que los disputantes parten de la posesión de un cierto saber consolidado por la experiencia, y de que entre personas razonables sólo se invocarán argumentos que posean un cierto peso específico. «De esta suerte -explica- cobra sentido la referencia a los «mejores y más famosos». La referencia a lo consensuado, ya sea entre los más o entre los mejores, proporciona asideros con cierto grado de admisibilidad en el campo de lo opinable ${ }^{76}$. En suma, el consenso preside la selección de los tópicos admisibles y enfrentados. Pero queda sin resolver el problema de la elección final entre esos tópicos concurrentes, igualmente legitimados en su punto de partida y carentes de una ordenación jerárquica clara.

Creemos que tiene razón Kriele cuando sostiene que los defensores de la tópica jurídica no establecen la relación entre los tópicos y la decisión jurídica final como si aquéllos fueran determinantes por sí solos de la solución del problema. Serían más bien propuestas de solución que se someten a discusión ${ }^{77}$. ¿Cómo recae esa decisión?

Nuevamente está en lo cierto Kriele al decir que la cuestión de los fundamentos para la opción por unos u otros de los tópicos sometidos a debate es respondida por los partidarios de la tópica de modo deliberadamente vago. Y también cuando afirma que la remisión al consenso aquí carece de utilidad, pues en los conflictos, precisamente por serlo, el consenso generalmente faltará y la variedad de posturas en la sociedad y entre los juristas permite una amplia escala de opiniones divergentes ${ }^{78}$. Esto

${ }^{75}$ TJ, p. 41-42 (trad. 60). Ramón SORIANO plantea correctamente la cuestión al señalar que los topoi constituyen «el ámbito del sentido común en el que suelen coincidir la mayoría de las personas» Compendio de teoría general del derecho, Barcelona, Ariel, 1983, p. 185.

${ }^{76}$ TJ, p. 42-43 (Trad. 61-62).

${ }^{77}$ KRIELE, M., Theorie der Rechtgewinnung, cit., p. 151.

${ }^{78}$ Ibid., p. 151-152. 
parece justificar la crítica de que la tópica como método no ofrece una pauta decisoria para la elección entre los tópicos invocados en la discusión ${ }^{79}$.

Ante esta situación, cabe pensar que la tópica es una doctrina abocada al puro decisionismo ${ }^{80}$; o entender, como creemos que es más justo, que como doctrina metodológica es sencillamente incompleta, debiendo ser complementada por principios o doctrinas tendentes a velar por la racionalidad de la decisión. En tal sentido se deben entender las afirmaciones de que la tópica jurídica no constituye una auténtica o suficiente teoría de la argumentación jurídica. Se quedaría en un primer estadio de una tal teoría, describiría únicamente los primeros pasos o el punto de despegue del proceso argumentativo que termina en la decisión. Sería, utilizando la certera expresión de Mengoni, un medio de selección de «hipótesis de solución» ${ }^{81}$.

\section{3. Tópica, precomprensión y evidencia.}

Que la tópica no proporcione indicaciones metódicas precisas para la elección entre las alternativas decisorias no significa necesariamente que decaiga en ella toda relevancia teórica y metodológica. Al lado de esa dimensión directiva de la metodología jurídica, está también su aspecto descriptivo y explicativo de los modos de proceder y los presupuestos de todo trabajo práctico con el derecho. Y es en esta dirección donde se puede buscar aún una aportación explicativa por parte de la tópica. Para ello no se ha de atender al punto final, es decir, la decisión, sino a los presupuestos de partida, a su apoyatura constante, que hace que las opciones decisorias se puedan plantear como tales en un contexto que les preste sentido y las haga capaces de aceptación y consenso. Por eso hay que puntualizar que nos estamos refiriendo ahora al consenso como «punto de partida» de la argumentación jurídica, para diferenciarlo del consenso sobre el «punto de llegada» $\mathrm{u}$ objetivo final de la argumentación y posible garantía de racionalidad de la decisión.

Nos referimos aquí a lo que, en palabras de Aarnio, es «el problema de las precondiciones últimas bajo las cuales nuestro conocimiento de la realidad (y de la sociedad) se constituye» ${ }^{82}$.

${ }^{79}$ Véase ALEXY, Theorie der juristischen Argumentation, Frankfurt/M., Suhrkamp, 1978, p. 42.

${ }^{80}$ Hans Welzel llegó a emparentar la tópica con el schmittiano «pensarniento concreto de orden». Véase al respecto, críticamente, LÜDERSSEN, K., Dialektik, Topik und «konkretes Ordnungsdenken» in der Jurisprudenz, en: Festschrift für Richard Lange, Berlín, de Gruyter, 1976, pp. 1.019 ss.

${ }^{81}$ Según MENGONI, «la tópica es un medio de control racional de la precomprensión, un instrumento para ponerla a prueba y obligarla a medirse con la «cosa» de que se trata, seleccionando, entre las hipótesis de solución pensables, aquellas objetivamente dotadas de sentido, es decir, abiertas a la crítica y a la corrección (Diritto e valori, Bolonia, Il Mulino, 1985, p. 41-42).

${ }^{82}$ AARNIO, A., The Signifiance of the Theoretical Element in Legal Research, en: AARNIO, Philosophical Perspectives in Jurisprudence, Helsinki, Societas Philosophica Fennica, 1983, p. 133. 
Ya hemos visto cómo Viehweg afirma que para que pueda plantear se un problema se presupone una comprensión provisional, un contexto dado previamente a la comprensión. En Viehweg la teorización en torno a este marco de contenidos comunes y previos al razonamiento sobre el derecho se lleva a cabo en su teoría de la Basisdoktrin como sustrato ideológico homogeneizador y generador de la dogmática, y de esta misma como garante de postulados jurídicos tenidos por generalmente aceptados e indiscutibles para el funcionamiento del derecho. El trabajo jurídico no opera simplemente sobre la base de unos tópicos surgidos de la conciencia social por no se sabe qué camino incierto, sino que existe, a la raíz de lo que en cada sociedad conforma el campo jurídico, todo un cuerpo de postulados y opiniones incuestionables y no sometidas a discusión, dogmatizadas. Este fondo dogmático representa un límite a la admisibilidad de tópicos como argumentos. El juego de los tópicos tendrá lugar solamente dentro de esos márgenes de compatibilidad con los que son tenidos por dogmas básicos de la comunidad jurídica. Dentro de dichos márgenes, la tópica es origen de esos que luego podrán ascender a nuevos dogmas. La tópica sería fuente de la dogmática y estaría, al mismo tiempo, limitada por ella. Estos dogmas no son mero producto de la comunicación en el marco jurídico, sino que son enunciados de la ideología social de base y han de permanecer concordantes con ella ${ }^{83}$.

También otros autores han teorizado ese consenso, como punto de partida de la argumentación, con expresa referencia a la tópica. Tal es el caso de Esser, para quien la formación del convencimiento supone la actuación dentro de ese espacio que denomina Sachlogik, «naturaleza de la cosa» o «evidencia». Se trata de reconducir todo juicio, con ayuda de valoraciones tópicamente argumentadas, a una plausibilidad enraizada en una especie de racionalidad social tenida por evidente, de retrotraer los argumentos a un nivel tal en que no se requiere ulterior argumentación, en cuanto que se alcanza un punto generalmente compartido. Añade Esser que «para ello son, por su propia naturaleza, especialmente aptos los argumentos tópicos, que tienden precisamente a ese efecto de coincidencia» $^{84}$.

Es necesario aclarar que cuando se habla de evidencia, de naturaleza de la cosa, etc., se pueden entender estas nociones cargadas de un componente ontológico, como alusivas a realidades constantes y dadas previamente y de una vez por todas, o, por el contrario, haciendo hincapié en su consideración como cristalizaciones históricas y cambiantes de lo que para el desenvolvimiento de cada sociedad es tomado por evidente

${ }^{83}$ Véase VIEHWEG, Ideologie und Rechtsdogmatik, en: MAIHOFER, W. (ed.), Ideologie und Recht, Frankfurt/M. Klostermann, 1969, pp. 86 ss; Veber den Zusammenhang zwischen Rechtsphilosophie, Rechtstheorie und Rechtsdogmatik, en: Estudios jurídico-sociales. Homenaje al profesor Luis Legaz y Lacambra, vol. 1, Santiago de Compostela, 1960, pp. 207 ss.

${ }^{84}$ ESSER, J., Vorverständnis und Methoden wahl der Rechtsfindung, Frankfurt/M., Athenäum, 2. ${ }^{\mathrm{a}}$ ed., 1972, p. 26-27. 
y generalmente admitido ${ }^{85}$. Cuando se hace referencia a la posible conexión entre la tópica y estos presupuestos primeros de la argumentación se los entiende siempre en este segundo sentido, como postulados contingentes, socialmente dependientes, históricamente condicionados y cumpliendo una función de «estabilizadores», por usar la expresión de Schreiner $^{86}$. Se dice que la tópica se apoya en un cierto consenso en torno a lo tenido por evidente, arranca de ciertos postulados situados en un punto tal que no se requiere para ellos en el seno social ulterior fundamentación argumentativa. Conectaría con unas «verdades comunes que no son racionalmente corregibles sin poner en peligro el consenso a ellas referido», ya que forman la «base de la conciencia general» ${ }^{87}$.

Merece destacarse la integración que por esta vía realizan algunos autores entre tópica y doctrina de la «naturaleza de la cosa». Ballweg, por ejemplo, sostiene que con la noción de naturaleza de la cosa se alude al problema como centro de la labor jurídica y elemento prioritario a tomar en cuenta para toda decisión. Puesto que la solución de los problemas no la proporciona el sistema; sino la tópica, afirma que «la forma jurídica de pensamiento de la «naturaleza de la cosa» es una tal técnica tópica que busca la solución del problema» ${ }^{88}$.

Pero es Baratta quien elabora un modelo más completo y significativo de la interacción entre esas dos vías metodológicas. Baratta pretende responder al problema central de la metodología jurídica mediante el tratamiento de la naturaleza de la cosa «como parte de una tópica jurídica», de manera que «se priva al principio de la naturaleza de la cosa de todo significado axiomático y se lo cualifica como una argumentación tópica de la retórica jurídica» ${ }^{89}$.

Ese problema principal del método jurídico que se trata de resolver es el referente al «momento subjetivo de la valoración», al «fundamento objetivo de los juicios de valor jurídicos». La propuesta de Baratta consiste en afirmar, siguiendo a Vico, que «el principio constructivo de las estructuras objetivas del mundo humano se ha de buscar en la actividad

${ }^{85}$ Sobre estos modos de entender la noción de «evidencia» para el derecho, ACHTERNBERG, N., Die Evidenz als Rechtsbegriff, en: ACHTERNBERG, Theorie und Dogmatik des Oeffentlichen Rechts, Berlín, Duncker \& Humblot, 1980, pp. 21-40; MAYER-MALY, Th., Der Jurist und die Evidenz, en: Internationale Festschrift für Alfred Verdross, Munich, Fink, 1971, p. 259-270.

${ }^{86}$ SCHREINER, H., Evidenz und Rechtsmethodologie, en: Objektivierung des Rechtsdenkens. Gedächtnisschrift für Ilmar Tammelo, Berlín, Duncker \& Humblot, 1984, p. 548.

${ }^{87}$ HAGEN, J. J., Soziologie und Jurisprudenz, Munich, Fink, 1973, p. 119.

${ }^{88}$ BALLWEG, O., Zu einer Lehre der Natur der Sache, Basel, Helbing \& Lichtenhahn, 1963, p. 68.

${ }^{89}$ BARATTA, A., Juristische Analogie und Natur der Sache, en: Mensch und Recht. Festschrift für Erik Wolf, Frankfurt/M., Klostermann, 1972, p. 149. 
del hombre y en su concreta historicidad $\iota^{90}$. Por eso la teoría de la naturaleza de la cosa se concibe como «búsqueda del principio heurístico que aclare la naturaleza axiológica de las estructuras del mundo humano», principio que se encuentra en «la relación dialéctica del hombre con su mundo», en la «dinámica histórica concreta». No se trata de perseguir el fundamento axiológico de la acción humana en una dialéctica de la idea, sino «del operar humano como proceso de objetivación del hombre en el mundo ${ }^{91}$. Esta dialéctica genera, como producto histórico de cada momento, una serie de «lugares comunes» en torno a los que se articula lo considerado plausible o razonable, y en lo que se puede sustentar la búsqueda de soluciones para cada concreto problema práctico ${ }^{92}$.

No parece descaminado ver en la tópica el intento metódico de articular la solución racional de los casos mediante la confluencia de un doble principio metodológico: la atención preponderante al problema y la consideración, como punto de arranque de toda propuesta resolutoria aceptable, de un entramado de postulados, directivas o creencias considerados evidentes en la sociedad de que se trate. De ahí que quepa, por un lado, decir que tesis fundamental de la tópica es «la afirmación de un conocimiento supraindividual, que está condensado en esos tópicos, en ese sentido común que se forma con el tiempo en el seno de los grupos sociales $\rangle^{93}$; y, por otro, vincular la noción de tópica a la naturaleza de la cosa como topos jurídicos que se basa en la búsqueda de la máxima decisoria atendiendo a «la concreta individualidad del caso ${ }^{94}$.

Se ha afirmado que el recurso a lo evidente es inevitable, por mucho que pueda cuestionarse su racionalidad ${ }^{95}$. Para contrarrestar los peligros de dogmatismo y arbitrariedad que ese apoyo metodológico pueda acarrear, se ha aludido en la doctrina a la necesidad de restringirlo lo más posible ${ }^{96}$, de ampliar al máximo el círculo de aquéllos cuya perspectiva se toma en cuenta ${ }^{97}$, de garantizar en todo momento la discutibilidad

${ }^{90}$ Ibid., p. 155, 156.

${ }^{91}$ Ibid., p. 158.

${ }^{92}$ Cfr. BARATTA, A., Die Theorie der Natur der Sache im Licht der «Neuen Rhetorik» en: BARATTA, Philosophie und Strafrecht, Köln, C. Heymann, 1985, p. 159 ss.

${ }^{93}$ LÓPEZ CALERA, N., Filosofía del Derecho, Granada, Comares, 1985, p. 183.

${ }^{94}$ BARATTA, A., Natur der Sache und Naturrecht, en: KAUFMANN, A. (ed.), Die ontologische Begründung des Rechts, Darmstadt, Wissenschaftliche Buchegesellgeschaft, 1965, p. 116.

${ }^{95}$ MAYER-MALY, Th., Der Jurist und die Evidenz, cit., p. 270.

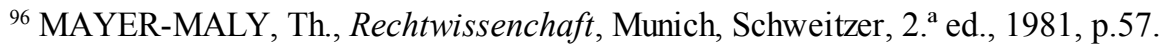

${ }^{97}$ ACHTERNBERG, N., Die Evidenz als Rechtsbegriff, cit., p. 39. 
de la opinión común ${ }^{98}$, y de considerar toda evidencia de este tipo como mediata y provisional, históricamente condicionada ${ }^{99}$.

En última instancia, este enfoque nos conduce a las mismas dificultades de toda fundamentación consensual de la racionalidad. Sentado que no se parte del acceso individual a una objetividad material y libre de duda, sino del establecimiento social de un «sentido común» con relevancia pragmática y valor de punto de inicio de la cadena argumentativa tendente a fundamentar opciones valorativas, el problema principal se liga con la extensión y la calidad del consenso de base. De ahí que se coloque el criterio último en la «vivencia efectiva de lo correcto por parte de los miembros de la respectiva comunidad jurídica» ${ }^{100} \mathrm{y}$ se mencione el consenso en el sentido de «único indicio verificable de la corrección social de ese orden normativo difuso en el cuerpo social» ${ }^{101}$.

La tópica es compatible e, incluso, necesita ser complementada con una teorización más precisa de la forma de articulación argumentativa de esos datos previos o puntos de apoyo del discurso. Existiría una tensión entre lo considerado evidente y la necesidad de decidir allí donde lo correcto no se impone en la dinámica social por sí mismo, sino que se enfrentan posiciones contrapuestas con base común en argumentos aceptables. En ese caso, no bastará una doctrina que constate la existencia de evidencias, opiniones generalmente admitidas o tópicos, ni que describa la mecánica de su interrelación en el discurso. Si se quiere responder a la demanda de racionalidad que preside el tratamiento del método jurídico, se ha de correlacionar todo esto con el trasfondo de una fundamentación argumentativa de las opciones decisorias. En este contexto, lo tenido por evidente o generalmente aceptado no se verá con caracteres absolutos, sino como cambiante y dependiente de la dinámica social. Será la índole de su utilización en una argumentación fundamentadora lo que puede servir como un cierto patrón para restar la impresión de anquilosamiento de esos elementos y de arbitrariedad en la elección de entre ellos, mostrando que «lo evidente» no proporciona una utilidad para un método decisorio racional si no es en el seno de su «comprensión argumentativa» ${ }^{102}$.

Es esta una línea que con frecuencia se insinúa en los escritos de la tópica jurídica, pero que casi nunca se desarrolla sistemáticamente y en profundidad.

${ }^{98}$ HORN, N., Rationalität und Autorität in der juristischen Argumentation, «Rechtstheorie», 6/1975, p. 157 ss.

${ }^{99}$ SCHREINER, H., Evidenz und Rechtsmethodologie, cit., p. 553-555.

${ }^{100}$ GARRN, H., Die «Natur der Sache» als Grundlage der juristischen Argumentation, «ARSP», 68/1982, p. 68.

${ }^{101}$ ESSER, J., Vorverständnis und Methoden wahl in der Rechtsfindung, cit., p. 27-28.

${ }^{102}$ Cfr. GARRN, H., Zur Rationalität rechtlicher Entscheidungen, Stuttgart, F. Steiner, 1986, p. 32-33. 